\title{
Metagenomic insights into the dynamics of microbial communities in food
}

\author{
Gilles Kergourlay $^{\mathrm{a}, *}$, Bernard Taminiau ${ }^{\mathrm{a}}$, Georges Daube ${ }^{\mathrm{a}}$, Marie-Christine Champomier Vergès ${ }^{\mathrm{b}, \mathrm{c}}$ \\ a University of Liège, Food Science Department, Fundamental and Applied Research for Animal and Health, Food Microbiology, Sart-Tilman B43b, B-4000 Liège, Belgium \\ b INRA, UMR1319 Micalis, F-78352 Jouy-en-Josas, France \\ c AgroParisTech, UMR Micalis, F-78352 Jouy-en-Josas, France
}

\section{A R T I C L E I N F O}

\section{Article history:}

Received 9 March 2015

Received in revised form 4 September 2015

Accepted 13 September 2015

Available online 16 September 2015

\section{Keywords:}

Metagenetics

Metagenomics

Microbial communities

Food microbiology

Food processing

Food storage

Fermented food

Cheese

\begin{abstract}
A B S T R A C T
Metagenomics has proven to be a powerful tool in exploring a large diversity of natural environments such as air, soil, water, and plants, as well as various human microbiota (e.g. digestive tract, lungs, skin). DNA sequencing techniques are becoming increasingly popular and less and less expensive. Given that high-throughput DNA sequencing approaches have only recently started to be used to decipher food microbial ecosystems, there is a significant growth potential for such technologies in the field of food microbiology. The aim of this review is to present a survey of recent food investigations via metagenomics and to illustrate how this approach can be a valuable tool in the better characterization of foods and their transformation, storage and safety. Traditional food in particular has been thoroughly explored by global approaches in order to provide information on multi-species and multi-organism communities.
\end{abstract}

(c) 2015 Elsevier B.V. All rights reserved.

\section{Introduction}

Metagenomics has become ubiquitous in the field of ecosystem exploration. Natural environments as diverse as air, soil, water, plants, as well as various human microbiota (e.g. digestive tract, lungs, skin) have been thoroughly explored by this approach, but food microbiota have until recently been less reported in the literature, perhaps because microbial communities of food are generally considered to have a low richness in terms of diversity. A long and well established tradition of determination of the main food contaminating species via cultural methods exists and has proven its efficiency for proposing and determining criteria and regulations in the field of food safety. However, this cultural approach has the drawback of detecting only cultivable bacteria, potentially only a small portion of the true microbial population (Giraffa and Neviani, 2001). At the beginning of 1990s, new approaches in the description of bacterial communities appeared through the development of culture-independent methods such as denaturing gradient gel electrophoresis (DGGE) (Muyzer et al., 1993), temperature gradient gel electrophoresis (TGGE) (Felske et al., 1998),

\footnotetext{
* Corresponding author.

E-mail addresses: gilles.kergourlay@ulg.ac.be (G. Kergourlay), bernard.taminiau@ulg.ac.be (B. Taminiau),georges.daube@ulg.ac.be (G. Daube), marie-christine.champomier-verges@jouy.inra.fr (M.-C. Champomier Vergès).
}

terminal restriction fragment length polymorphism (T-RFLP) (Marsh, 1999), and several other automated PCR-based techniques still widely used today, such as temporal temperature gradient gel electrophoresis (TTGE) (Mace et al., 2012). Most of these methods allow accurate identification of part of the microbial community through the sequencing of ribosomal 165 rDNA targeted gene. Then, in the mid to late 1990s, two new methods for DNA sequencing were developed by Ronaghi et al. (1996) and Mayer et al. (1997), the pyrosequencing and the parallelized ligation-mediated and bead-based sequencing, respectively. Together, these two methods were considered as the "Next-Generation Sequencing" techniques (NGS). In the mid2000s, commercially available sequencers based on these methods appeared (454 Life Science) leading to a revolution in the study of microbial ecosystems with the possibility of high-throughput sequencing of genes (HTS).

The development of these NGS technologies and their application in the field of food ecosystems revealed that these communities were perhaps more rich than expected and that some of them might play a yet unsuspected role. Ercolini (2013) recently reviewed high throughput workflow for food analysis by HTS. The use of these sequencing technologies to study food microbial communities is still relatively new, but its popularity is currently booming and its use has become affordable not only for researchers but also for the food industry as several companies now provide these services. The aim of this paper is to have an overview of information gained by this NGS approach to further our 
understanding of food ecosystems. We will focus in particular on the bacterial aspect of microbiota since many publications, using NGS for microbial food description, target the 16S rDNA gene. Yeast and filamentous fungi play a key role in food just as bacteria does, but the use of NGS to decipher an eukaryote ecosystem requires a different approach, targeting the internal transcribed spacer (ITS) region, a noncoding DNA sequence situated between the small-subunit ribosomal RNA (rRNA) and large-subunit rRNA genes in the chromosome. The ITS database is somewhat less advanced than for the 16S rDNA gene, but will gradually improve over the next few years (Santamaria et al., 2012). Nevertheless, some interesting reviews have already addressed this topic (Wolfe and Dutton, 2015). Specific challenges for food will be addressed and illustrated in the remainder of this paper.

\section{Revisiting our vision of known foods}

\subsection{Metagenomics and metagenetics: a matter of scale and target}

Metagenomics, based on gene fragment DNA sequencing, refers to the analysis of genetic material coming directly from the environment. In fact, in most cases the so called "metagenomic studies" are based on the analysis of a single type of gene: the 16S rRNA encoding gene, which is the most powerful marker for the identification of bacterial species and phylogenetic studies. Sequencing randomly amplified DNA fragments as per the metagenomic approach is less often reported, especially in food. It has been proposed that the term metagenetics may be restricted for studies dealing with 16S (Esposito and Kirschberg, 2014). In the field of food, mainly $16 \mathrm{~S}$-based studies have been performed.

The availability of new and affordable molecular techniques to characterize microbial flora has aroused interest regarding the potential to overcome classical microbiology limitations, or more accurately, to complement traditional microbiology with culture-independent strategies. Thereby, several kinds of food products, both fermented and unfermented, have been investigated using this duel-approach. In this way, the field of cheese making can be used to illustrate and summarize the various goals and concerns, which can be addressed by metagenetics and metagenomics. We will refer to two recent reviews for further readings (Irlinger et al., 2015; O'Sullivan et al., 2013).

\subsection{Cheese: a product of interest}

Cheese processing starts with fermentation by lactic acid bacteria (LAB). During this process, cheese evolves into 2 distinct parts: the inner core and the external rind, in which the microbiota and their interactions are different. The microbial populations originate either from raw products or from starter cultures; then other populations progressively replace the dominant starters during ripening. These starters, mainly LAB, induce the early acidification process, while the non-starter microbiota (which include bacteria but are also comprised of yeasts, molds, and filamentous fungi (Fox et al., 2000)), is involved in flavor, ripening or smear cultures.

Although numerous studies using molecular techniques (e.g. qPCR, DGGE, TRFLP) had already been published, the first extensive description of cheese bacterial microbiota with 16S metagenetic analysis by Quigley et al. (2012) set a new milestone with the first detection of several bacterial genera in cheese, such as Prevotella or Arthrobacter. Since this first publication on Irish cheese, the majority of the descriptive reports target a specific cheese type: water buffalo mozzarella cheese (Ercolini et al., 2012), Latin-style cheese (Lusk et al., 2012), Croatian cheese (Fuka et al., 2013), Belgian Herve cheese (Delcenserie et al., 2014), and Mexican Poro cheese (Aldrete-Tapia et al., 2014). This overview of traditional cheese studies was completed by two transversal studies on several kind of cheese (Almeida et al., 2014; Wolfe et al., 2014). All these studies assessed the microbial diversity in complement with classic microbiological culture. They revealed that cheese rind possesses a dominant core of 14 bacterial and 10 fungal genera (Irlinger et al., 2015; Wolfe et al., 2014). This core is completed by more specific sub-dominant populations, which are thought to be active in the cheese ripening and aging. The analysis of the flora detected by HTS and by classic microbiology reveals significant differences. Metagenetics capture a broader range of bacterial population where bacterial cultivation and isolation can often be more thorough in terms of identification and characterization. The limits of metagenomics are well known: the length of sequencing fragments, the depth of sequencing effort, and bias on DNA extraction and amplification. However, it should be emphasized that microbiological media and culture conditions are biased too, since they often favor compatible and cultivable bacteria over more slow-growing and non-cultivable populations.

Beyond the ecology of cheese microflora, these HTS surveys were often performed regarding specific concerns. First, the characterization of a particular cheese with a protected specific appellation will be useful to underline and explain its typicality (Aldrete-Tapia et al., 2014; Delcenserie et al., 2014; Fuka et al., 2013). Second, the main goal is to develop a better understanding of the fabrication process (Bokulich and Mills, 2013; Ercolini et al., 2012; O'Sullivan et al., 2013, 2015). Metagenetics can be applied to various types of samples to identify spatial and temporal variations during cheese processing. In particular, O'Sullivan et al. (2015) have shown that during a day of production, late cheeses tend to present a higher bacterial diversity than early cheeses and that this diversity is persistent during the ripening process, which is a concern when traditional cheese makers want to scale up and standardize specific or raw milk cheeses. HTS analysis can be a powerful tool to measure the impact of process changes on the typical microbiota (Aldrete-Tapia et al., 2014; Fuka et al., 2013).

Finally, global metagenomics has been used in order to improve the functional knowledge of cheese products. In a first publication, Wolfe et al. (2014) described in situ and in vitro studies of rind formation in which they isolated bacterial and fungal populations and observed bacterial/fungal interactions. More precisely, using a metagenomic approach they studied the cheese rind microbial communities of 137 different cheeses across ten countries and revealed a widely distributed dominant community of 24 culturable genera of bacteria and fungi. The authors first investigated how taxonomic diversity varies within the three rind types studied: bloomy, natural, and washed. They then revealed putative functions of uninoculated organisms, such as the presence of methionine-gamma-lyase (MGL) (an enzyme responsible for the production of sulfur compounds in cheese), which has previously been reported only in Brevibacterium linens (Amarita et al., 2004) and was reported here in Pseudoalteromonas. Following this in situ study, authors proceeded to an in vitro experiment by culturing a representative cheese rind community composed of (at least) one isolate from the 24 dominant genera previously identified. By doing so they highlighted the importance of abiotic manipulations by cheese makers in the selection of specific microorganisms. This in vitro approach also allowed an easier way to describe interactions within the cheese rind communities, for example between bacteria and fungi.

A second paper by Almeida et al. (2014) performed massive genomic sequencing and functional metagenomic profiling of cheese samples. The authors selected 142 bacteria isolated from dairy products belonging to 137 different species and 67 genera. Via massive sequencing, they were able to reconstruct 117 genome drafts. Through their work, they actually doubled the number of sequenced genomes of known bacteria linked to cheese products with the ambition of building a functional genomic catalog dedicated to cheese bacteria. They also analyzed the microbial composition of communities present at the surface of different traditional cheeses and observed that a significant proportion of the species were present in the newly sequenced genomes part of their catalog. This revealed that some species not initially inoculated, named Psychrobacter immobilis and Pseudomonas haloplanktis, were in fact present as dominant species. 
Table 1

Fermented products characterized using high-throughput $16 \mathrm{~S}$ rRNA gene sequencing.

\begin{tabular}{|c|c|c|c|c|c|}
\hline Type & Product & Product & Domain & Country & Ref. \\
\hline \multirow[t]{15}{*}{ Food } & Dairy & Mongolian dairy products & Bacteria & Mongolia & Oki et al. (2014) \\
\hline & Condiment & Kochujang (Korean condiment) & Bacteria & Republic of Korea & Nam et al. (2012b) \\
\hline & \multirow[t]{3}{*}{ Fish } & Narezushi (Japanese fish with rice) & Bacteria & Japan & Kiyohara et al. (2012) \\
\hline & & Kaburazushi (Japanese medieval sushi) & Bacteria & Japan & Koyanagi et al. (2013) \\
\hline & & Flatfish jeotgal (Korean fish) & Bacteria & Republic of Korea & Jung et al. (2014) \\
\hline & \multirow[t]{2}{*}{ Legume } & Doenjang (Korean soybean pastes) & Bacteria & Republic of Korea & Nam et al. (2012a) \\
\hline & & Lu-Doh-Huang (Taiwanese mung beans) & Bacteria & Taiwan & Chao et al. (2013) \\
\hline & Meat & Italian salami & Bacteria & Italy & Polka et al. (2015) \\
\hline & \multirow[t]{2}{*}{ Seafood } & Several different seafood & Bacteria/archeae & Republic of Korea & Roh et al. (2010) \\
\hline & & Ojingeo jeotgal (Korean squid) & Bacteria & Republic of Korea & Jung et al. (2013a) \\
\hline & \multirow[t]{2}{*}{ Seed } & Cocoa bean & Bacteria/fungi & Belgium & Illeghems et al. (2012) \\
\hline & & Meju (Korean soybean bricks) & Bacteria & Republic of Korea & Kim et al. (2011) \\
\hline & \multirow[t]{3}{*}{ Vegetable } & Kimchi (Korean vegetables) & Bacteria & Republic of Korea & Park et al. (2012) \\
\hline & & & Bacteria & Republic of Korea & Jung et al. (2011) \\
\hline & & Nukadoko (Korean vegetable in rice bran) & Bacteria & Japan & Sakamoto et al. (2011) \\
\hline \multirow[t]{12}{*}{ Liquid } & \multirow[t]{3}{*}{ Alcohol } & Makgeolli (Korean alcoholic beverage) & Bacteria/fungi & Republic of Korea & Jung et al. (2012) \\
\hline & & Fen liquor (Chinese liquor) & Bacteria/fungi & Chinese & Li et al. (2013) \\
\hline & & Shaoxing wine (Chinese rice wine) & Bacteria & China & Xie et al. (2013) \\
\hline & Condiment & Chinese soy sauce & Bacteria/yeast & Malaysia & Sulaiman et al. (2014) \\
\hline & \multirow[t]{5}{*}{ Milk/fruit } & \multirow[t]{5}{*}{ Kefir (milk or fruit juice beverage) } & \multirow[t]{5}{*}{ Bacteria/yeast } & 8 regions & Marsh et al. (2013b) \\
\hline & & & & Ireland & Dobson et al. (2011) \\
\hline & & & & Ireland & Marsh et al. (2013a) \\
\hline & & & & Turkey & Nalbantoglu et al. (2014) \\
\hline & & & & Brazil & Leite et al. (2012) \\
\hline & Plant & Chicha (maize-based beverage) & Bacteria & Argentina & Elizaquivel et al. (2014) \\
\hline & \multirow[t]{2}{*}{ Tea } & Kombucha (Mongolian tea) & Bacteria & Mongolia & Marsh et al. (2014) \\
\hline & & Pu'er (Chinese tea) & Bacteria & China & Lyu et al. (2013) \\
\hline
\end{tabular}

Such studies using metagenomics are still scarce, since the sequencing and bioinformatic costs are higher than for metagenetics. However, the richness of information obtained by this approach is certainly worth the investment, and the number of studies based on this technology is expected to rapidly increase.

\section{Characterizing fermented food}

\subsection{An overview of traditional products}

Fermented food products have been widely explored by metagenetics, in particular traditional fermented vegetal food from Asia. Table 1 reports the most significant of these studies. The metagenetic approach offers the opportunity to gain information on communities less explored by classical cultural methods. Humblot and Guyot (2009) reported the first study using metagenetics to decipher fermented food; the study deals with the analysis of pearl millet slurries, a traditional fermented gruel consumed in Burkina Faso. This demonstrated the feasibility of the method for rapidly gaining information about less characterized fermented products of various origins and in particular from different vegetal substrates. To date, a large number of fermented food and beverages have been analyzed worldwide, especially in Asia. This approach has proven to be a powerful tool for exploring natural diversity and tracking fermentation processes. The microbial communities responsible for these spontaneous fermentations are often composed of mixed LAB species and using NGS approaches appears to be an efficient way to evaluate their evolution during these natural fermentation processes.

These approaches also led to the finding that some unsuspected organisms could be present in the food we eat. As an example, Roh et al. (2010) revealed that archaebacteria were widely represented in Korean fermented seafood products (Jeotgal).

Among these examples stands the case of sourdough. Sourdough starters are composed of yeasts and bacteria, generally LAB. Using these starters for bread making is a traditional ancient method. A study by Ercolini et al. (2013) followed the respective evolution of yeast and bacteria in sourdough. Several taxonomic groups were identified with a rapid evolution: after 1 day the structure of the population was drastically modified. Some species appear as subdominant and were not detected by cultural methods.

\subsection{Focus on the most commonly studied fermented products}

\subsubsection{Kefir, a symbiotic community-fermented beverage}

Kefir is another product fermented with both yeasts and bacteria. This much-studied beverage can be obtained from the fermentation of milk or water with sucrose and fruits added, commonly figs. The latter is then called water kefir. The metagenetic approach highlighted that the bacterial community of kefir grains is dominated by the genera Lactobacillus. Within this genera 3 species are dominant: Lactobacillus kefiranofaciens, Lactobacillus buchneri, and Lactobacillus helveticus. Other genera, such as Lactococcus and Leuconostoc, were also identified at low levels (Korsak et al., 2015; Leite et al., 2012; Nalbantoglu et al., 2014). Otherwise, the kefir milk fermentate was rather dominated by Streptococcaceae and primarily the genera Lactococcus (Dobson et al., 2011). Considering yeasts, the genera Kazachstania, Kluyveromyces, and Saccharomyces dominated this community (Leite et al., 2012; Marsh et al., 2013b). Regarding the water kefir community, it was found to be quite different since Zymomonas was the dominant bacterial genera ahead of Lactobacillus, whereas Dekkera, Hanseniaspora, and Saccharomyces dominated the yeast community (Marsh et al., 2013a).

\subsubsection{Fermented seafood, a culinary specialty originally from Asia}

Until recently, the microbial diversity of fermented seafood products remained predominantly undescribed, in comparison with other products such as fermented dairy products, for example. However, in the last few years NGS have been widely used to study fermented seafood, especially in Asia. Korea, in particular, is at the forefront of this area of research since fermented seafood, called jeotgal, is broadly consumed. Jeotgal consists of a natural fermentation of highly salted seafood products such as oysters, shellfish, shrimp, and fish with more than 150 different varieties listed (Lee et al., 2014). Roh et al. (2010) studied the microbiota of seven of them with barcoded pyrosequencing using the original approach to describe Bacteria and Archaea together. Most of the identified sequences were classified as Archaea and related to the halophilic family Halobacteriaceae and the mesophilic phylum 
Crenarchaeota. However, with less than 2000 identified sequences, authors highlighted that six (shrimp, shellfish, cuttlefish, roe of pollack, tripe of pollack, and crab) of the seven products were mostly composed of two genera of the LAB group, Lactobacillus and Weissella, which were present in various proportions depending on the product considered. Only one jeotgal (based on oyster fermentation) seemed different, with halophilic Salinivibrio as the dominant genus (89.5\%). According to the authors, LAB seem very important in the fermentation process of seafood but these results are contradicted by Jung et al. (2013a), who showed that in Saeu-jeot (a jeotgal based on shrimp fermentation) LAB are a minor population such as Archaea, which are stable over time. Thus, they described the microbial succession during the fermentation process and highlighted that Proteobacteria were dominant at the beginning of the fermentation, including Pseudoalteromonas, Photobacterium, and Vibrio, but were rapidly overcome a the early phase of the process by Firmicutes such as Staphylococcus, Salimicrobium, and Alkalibacillus. Next, this population also decreased and the genus Halanaerobium became the dominant population until the end of the fermentation.

In another publication, Lee et al. (2014), the same team studied the effects of different temperatures $\left(10^{\circ} \mathrm{C}, 15^{\circ} \mathrm{C}, 20^{\circ} \mathrm{C}\right.$, and $\left.25^{\circ} \mathrm{C}\right)$ on the fermentation process of this jeotgal. They showed that Proteobacteria remained dominant longer at low temperatures $\left(10^{\circ} \mathrm{C}\right.$ and $\left.15^{\circ} \mathrm{C}\right)$ but, finally, it was always Firmicutes that became the major population, with the exception that at these temperatures the dominant genus was Salimicrobium instead of Halanaerobium. Authors crossed the metagenetic analysis with a metabolomic approach using (1)H NMR. They showed that the dominant genus Halanaerobium was responsible for the production of acetate, butyrate, and methylamines at the highest temperatures. According to this multi-omic analysis, authors were able to recommend a theoretical temperature of $15{ }^{\circ} \mathrm{C}$ to get an optimum Saeu-jeot fermentation. Jung et al. (2013a) studied another jeotgal, Ojingeo, based on squid fermentation. Unlike Saeu-jeot, Proteobacteria and Firmicutes were present in equal proportions at the end of the fermentation process. Moreover, a genus from the LAB group was the dominant population since Leuconostoc represents more than $35 \%$ of the total microbiota followed by Bacillus, Staphylococcus, and Psychrobacter, each representing about 10\%. Leuconostoc citreum and Leuconostoc holzapfelii seem to be the dominant species. The authors also investigated the presence of osmotic stress-related genes in the genomes of the three most abundant genera and the three rarest ones to estimate the importance of high concentrations of $\mathrm{NaCl}$ on bacterial diversity. They did not show significant results and hypothesized that more complex factors could be selecting the dominant bacterial species. Another Korean traditional fermented seafood closely related to jeotgal (named sikhae) was investigated with NGS by Kim et al. (2014). Based on flat fish fermentation, gajami-sikhae, in contrast to jeotgal, present lower concentration in salt $(<7 \%)$ and include cooked grains, among other ingredients. These differences lead to bacterial diversity changes since Lactobacillus was found to be the dominant genus in seven of the eight samples tested, with Leuconostoc dominating the other one. Weissella was also present, at a varying rate of less than $1 \%$ to about $50 \%$ of the total microbiota depending on the samples. These results are very close to those of Roh et al. (2010) previously described and suggest that Lactobacillus plays an important role in the seafood fermentation process. Thus, in addition to being the dominant population of most of the samples of gajami-sikhae and several jeotgal, Lactobacillus is also highly present in two additional fermented seafoods from Japan: kaburazushi and narezushi (Koyanagi et al., 2011, 2013). These traditional fish-based products are precursors of the modern unfermented sushi and were originally prepared to preserve them from spoilage. Kaburazushi comprises fish, turnip and malted rice. Lactobacillus plays a leading role in the fermentation process since this genus was found to represent $86 \%$ of the kaburazushi microbiota at the end of the fermentation process and only $2 \%$ at the beginning. It could prevent growth of other bacteria such as Staphylococcus and Bacillus, which represented $76 \%$ and $19 \%$ of the total reads, respectively, at the early phase of the process and less than $10 \%$ at the end (Koyanagi et al., 2013). Narezushi is quite different from kaburazushi, with boiled rice instead of malted rice and a longer period of fermentation ( $>1$ month). In the six samples of kaburazushi described by Koyanagi et al. (2011), Lactobacillus was again the dominant genus with 79 to $97 \%$ of the total reads in five of the samples. At a species level, Lactobacillus sakei dominated only one sample, Lactobacillus plantarum dominated three of them and Lactobacillus acidipiscis the other one, showing a significant variance in the dominant species.

Finally, since fermented seafood is produced with no sterilization or the use of starter culture, its microbiota is broadly dependent on the microbial community found on the ingredients, the incidentally occurring microbial species and the selection pressure exerted during fermentation. Thus, the microbiota of this kind of fermented product is not so well controlled as that of wine or dairy products, for example, but LAB and especially Lactobacillus seem to play a significant part in the fermentation process.

\subsubsection{Kimchi, the "-omics" approach of vegetable fermentation}

Kimchi is a traditional Korean food naturally fermented from vegetables such as cabbage and radish and various seasonings including garlic, ginger, red pepper powder, jeotgal, and salt and seems to provide health benefits (Park et al., 2014). Kimchi has been widely studied and NGS have been recently used to decipher its microbiota. Thus, different aspects of this microbial community have been addressed using all the current "-omics" tools: metagenetics (Jeong et al., 2013; Lee et al., 2015; Park et al., 2012), metagenomics (Jung et al., 2011), metabolomics (Jeong et al., 2013; Jung et al., 2011), and metatranscriptomics (Jung et al., 2013b).

The metagenetic approach has facilitated a better understanding of the microbial community and its dynamics during fermentation. Thus, Park et al. (2012) described the bacterial populations of ten representative kinds of kimchi. Indeed, there are many varieties of kimchi, depending on ingredients and local recipes. Most studies focused on the most popular one, baechu-kimchi, based on cabbage fermentation (Jung et al., 2011). Authors have shown that a majority of reads were assigned to two phyla: Proteobacteria and Firmicutes. The phylum Proteobacteria dominated at the early phase of the fermentation for most of the samples but was rapidly replaced by Firmicutes, which dominated at the end of the fermentation for the ten samples. The same three genera were identified at various levels of all studied kimchi: Lactobacillus, Weissella, and Leuconostoc. When Protebacteria was dominant at the early phase, Enterobacter, Vibrio, and Pseudomonas were the most represented genera. Interestingly, when Leuconostoc was used as starter culture, differences were observed in the microbial community compared with uninoculated kimchi at the early stages of fermentation, but not in the late phase. The study authors highlighted that the bacterial diversity evolution during fermentation could be explained by the processes and the major ingredient. Thus, some ingredients with an important bacterial community, such as jeotgal, became the major source of diversity in the early phase of the fermentation. Lee et al. (2015) went further by trying to find the source of $\mathrm{LAB}$ in the raw materials used to prepare kimchi and hypothesized that garlic and ginger could be the two major source of contamination. They also described the succession of LAB during the fermentation of five kimchi samples prepared with different sets of raw materials. They showed, in agreement with Park et al. (2012), that Lactobacillus, Weissella and Leuconostoc were the three dominant genera in kimchi fermentation. At a species-level, Weissella and Lactobacillus were found to be almost exclusively composed of only one species, Weissella koreensis and L. sakei, respectively, and two predominant species for Leuconostoc: Leuconostoc mesenteroides and Leuconostoc inhae. The authors concluded that, since the microbial diversity of kimchi appears to depend, in part, on raw material microbiota, it could be necessary to use a starter culture to achieve a homogenous and reproducible kimchi.

The metagenomic approach, just as a metagenetic approach, enables us to describe the microbial diversity in an ecosystem, but also goes further by sequencing all genes from a microbiota and not only 16S rRNA 
ones. For this reason, Jung et al. (2011) used a metagenomic approach to study the microbial composition and evolution of kimchi during fermentation. Apart from the description of the microbial ecosystem, the authors also studied different group of genes. They found a large number of phage DNA sequences and hypothesized that this could be due to infection by bacteriophages during fermentation, which could play a role in the microbial community dynamics. They also showed that carbohydrate fermentation seems to be a key category of genes to enable survival in this ecosystem, such as the metabolism of monoand oligosaccharides, which are feature of heterotrophic bacteria.

The metabolomic approach combines strategies to identify and quantify all metabolites in an ecosystem by using analytical technologies such as NMR or mass spectroscopy. It could be very useful to know which metabolites are produced by bacteria. Jung et al. (2011) monitored the development of free sugars, which play a significant part in the taste of kimchi and could be, in addition, a carbon source for the bacterial community (Ha et al., 1989). They showed that glucose and fructose decreased at the early and middle phase of the fermentation, while lactate, acetate, and ethanol increased. This is a feature of a heterotrophic bacteria-driven fermentation. LAB also produced mannitol: a substance used as sweetener, cohesion agent, and excipient in food. Jeong et al. (2013) also reported the concurrent production of GABA and succinate. From the middle phase onwards, free sugars stabilized due to the end of their fermentation by LAB. After 30 days of fermentation, the authors related that the concentrations of glucose and fructose once again started to decrease, this time without the production of lactate and acetate. They hypothesized that this could be due to a second fermentation led by Saccharomyces, which could also explain the decrease in amino acid from the middle phase of the fermentation onwards.

The metatranscriptomic approach consists of sequencing the total mRNA from an ecosystem using high-throughput sequencing technologies. It enables us to decipher a microbial community at a more detailed scale and understand how this community responds to changes in its environment. Jung et al. (2013b) used a metatranscriptomic approach to decipher the dominant species in Kimchi. They confirmed previous results about microbial succession by focusing on changes in the overall gene expression of the microbiota during kimchi fermentation. Thus, focusing on $W$. koreensis the authors showed that its gene expression was high at the end of the fermentation, when it is found as a major population of a low $\mathrm{pH}$ kimchi. They correlated this late emergence with the high expression rate of stress resistance genes, especially $\mathrm{pH}$ resistance ones, which could explain the acid tolerance of this species. On the contrary, L. mesenteroides, a low acid tolerance species, was found to be more active during the early phase of the fermentation. This species was identified (as for all Leuconostoc species) to be responsible for the mannitol production because several copies of mannitol dehydrogenase-encoding genes $(\mathrm{mdh})$ related to $L$. mesenteroides were found. The authors also showed that many genes were involved in fermentation and carbohydrate transport and hydrolysis. They found genes coding for homo- and heterofermentative enzymes, showing that both pathways occurred during kimchi fermentation, contrary to what was shown in previous studies. Some interesting features were highlighted, such as presence of genes for the production of vitamins (folate and riboflavin) and the absence of amino acid decarboxylase genes responsible for biogenic amine production.

Use of the different "-omics" technologies to study Kimchi allows a combinational analysis of the microbiota and metabolites. This approach enables us to better understand the relationship between a food product and its microbiota to a scale never reached before.

\section{Effects of processing and storage on food microbiota}

\subsection{Evolution of microbial population within a foodstuff}

Food preservation is a major concern for food technologists, industry and consumers. It still remains a challenge to predict the evolution of microbial communities during storage and processing. The opportunity to have an available method capable of characterizing dominant and sub-dominant populations during storage has constituted a precious tool in understanding the population dynamics and to easily compare different storage conditions or processes. This is particularly relevant for fresh products stored at low temperature such as meat or vegetables.

Concerning vegetables, Lopez-Velasco et al. (2011) used the $16 \mathrm{~S}$ rDNA pyrosequencing approach to track the dynamics of microbial communities on fresh spinach and compared the effect of two storage temperatures: 4 or $10^{\circ} \mathrm{C}$. At the beginning of storage, the initial community was rather low: 11 phyla were detected mainly represented by alpha, beta and gamma Proteobacteria. This diversity rapidly dropped during storage after one day. Pseudomonas and Enterobacteriaceae were the most significant after 15 days of storage. The study showed that abundance and diversity were modified during storage at a low temperature with the selection of psychrotrophic bacteria present as a consequence of low temperature storage.

Zhao et al. (2014) studied the microbial communities of chilled pork during long-term storage ( 21 days) at $0{ }^{\circ} \mathrm{C}$ under vacuum packaging in heat-shrink bags. They observed a large diversity (more than 200 bacterial species) at day 0 , but they could also detect that day seven of storage constituted a critical point where diversity changed. Primarily, Micrococcaceae, which were abundant at the beginning of the storage period, greatly diminished. At day seven, Aeromonadacae and Puniceicoccae were detected at high levels. After that time, the population was characterized by a drastic diminution of these communities, which were no longer detected as dominant populations, whereas the Lactobacillaceae increased and constituted the dominant flora after 21 days of storage.

Regarding meat, Xiao et al. (2013) have studied Zhenjiang Yao meat: a traditional refrigerated cooked, marinated and jellied pork meat in China. As observed in fresh pork meat, here also critical points in the evolution of microbial diversity were observed. During the early stage of storage (until day 7), Vibrio was the dominant genera whereas Lactobacillus, Lactococcus, Yersinia and some other Enterobacteriaceae dominated at day 15 . After 30 days of storage the population was quite different, with a high level of Vibrio. Similarly, Benson et al. (2014) studied refrigerated pork sausage dynamics during storage and under different processes. They also mentioned a complex diversity at day 0 and different phases of population change during a long-term storage. Moreover, they could correlate these changes to chemical profile modifications. They also showed that treatment with lactate/diacetate had a dramatic impact on these dynamics, characterized by a monophasic growth curve of a given species, i.e. Lactobacillus graminis. Interestingly, they could also track the origin of this species that seemed to have originated from spices used for the formulation of the sausages. They also correlated the presence of different species patterns to chemical changes in the matrix attesting spoilage.

\subsection{A revisited version of bacterial spoilage}

Food spoilage is defined as any change that renders a product unacceptable for human consumption (Huis in 't Veld, 1996). This spoilage has important consequences because its leads to important food losses and waste. Thus, the FAO estimated, in 2009 , that $32 \%$ of all food produced in the world was lost or wasted. Moreover, in developed countries $9 \%$ of theses losses happen at the handling or storage step where a great part of the spoilage takes place (Lipinski et al., 2013).

\subsubsection{Metagenetics as a tool to describe food spoilage}

Several approaches can be considered to use NGS technology and metagenetics as a tool to study food spoilage.

A first approach, chosen by Pothakos et al. (2014) is to study already spoiled products before the end of their shelf life. They used highthroughput sequencing of $16 \mathrm{~S}$ rDNA to describe the microbial communities involved in several food spoilage cases from different groups of 
products (i.e. meat, dairy, vegetable, egg products, and composite food) occurring in retail foodstuffs in Belgium prior to the end of shelf life in order to identify some spoilage-specific microorganisms. Despite the various origins or packaging of these products, authors related a relatively low phylogenetic diversity. The same psychrotrophic LAB were usually identified. Thus, the genus Leuconostoc (especially Leuconostoc gelidum and Leuconostoc carnosum) dominated the bacterial composition of three of the seven products studied (turkey, niçoise salad, and eggs) and the genus Lactobacillus (especially Lactobacillus sanfranciscensis, L. sakei and Lactobacillus algidus) dominated in two additional products (ham salad and salad with bacon). Weiseilla viridescens was identified as the principal spoiling species of mozzarella. Authors highlighted that these specific-spoilage organisms (SSO) were underestimated by classical mesophilic enumeration methods due to their psychrophilic character (Ercolini et al., 2009). These psychrophilic Gram-positive bacteria have been selected by hurdle technologies based on low-temperature storage and packaging (Audenaert et al., 2010) but some other non-LAB species have been identified, such as Pseudomonas fragi and Brochothrix thermosphacta (which dominate the microbiota of fish salad) and, unexpectedly, Xanthomonas hortorum (a plant pathogen found in ham salad).

Another approach in using metagenetics as a tool to study spoilage is to focus on the origin of spoilage-associated bacteria such as De Filippis et al. (2013). They studied the environmental occurrence and contamination routes in food manufacturing for beefsteaks. More precisely they analyzed, in 2 different slaughterhouses: 1 ) carcass swabs from beef cuts; 2) beefsteaks from this carcass before and after aerobic storage; and 3) swabs of the butchery environment where the beef was handled in order to explore the sources of the beefsteaks' bacterial contamination throughout the processing line. Several sources of possible contamination exist, such as the endogenous microbiota of the animal, environmental bacteria, and handling (Sheridan, 1998). In this study, samples were collected from the carcass (three beef cuts), butchery environment (chopping broad, cold store, hand, and knife), and beefsteaks (from the same three beef cuts at day 0 and after 6 days under aerobic condition). The authors highlighted a high diversity level in the carcass, the environmental samples, and in the beefsteak. Thus, 15 different phyla were identified in the carcass swabs and 12 in the beefsteak at day 0 . A significant decrease in the microbial diversity occurred at day 6 since only five phyla were detected on spoiled beefsteak, including Firmicutes and Proteobacteria. More precisely, Pseudomonas sp. and B. thermosphacta (which are known for their spoilage ability) together represented more than $80 \%$ of the microbial community. Acinetobacter sp. and Psychrobacter sp. were also present at a low level. Moreover the type of beef cut seems to influence the composition of the bacterial microbiota. For example, Pseudomonaceae significantly dominated hick-flanks of the carcass but not the two other beef cuts (brisket and chucks) recognized as the most soiled part by beef exudates (Yalçln et al., 2001). According to this study, most of the species identified in the butchery environmental swabs were also found in the beefsteaks such as Staphylococcus equorum, Propionibacterium acnes, Psychromonas arctica, Psychrobacter sp., B. thermosphacta, and Pseudomonas sp., but only the last three species grew because of their adaptation to the meat environment and low temperatures and a better competitiveness (Doulgeraki et al., 2012). The beta diversity analysis indicated that microbial compositions of swabs from the butchery environment of the two slaughterhouses were very closely correlated. The authors therefore highlighted that this could indicate a co-occurring microbial community. They also hypothesized the vector of contamination of beefsteaks by spoilage-associated bacteria. These bacteria, found originally on the carcass, are carried to the butchery environment by handling, where they become a resident flora. Beefsteaks are then contaminated by this flora during processing, and the most adapted bacteria will subsequently grow and spoil the product.

A third approach in using metagenetics as a tool to study spoilage is to describe the evolution of food microbiota during aging until spoilage appears. In this way Chaillou et al. (2014) described the evolution of bacterial communities associated with meat and seafood spoilage. Eight products were selected. Four were different meat products: ground beef, ground veal, poultry sausage, and diced bacon. The remaining four were different seafood products: smoked salmon, cooked peeled shrimp, salmon fillet, and cod fillet. Pyrosequencing analyses were realized as soon as possible after collection $\left(\mathrm{T}_{0}\right)$ and once spoilage had been clearly established $\left(T_{S}\right)$. First, the authors highlighted some bacterial communities by clustering $\mathrm{T}_{0}$ samples within three scales: 1) a general core community with ubiquitous bacteria originated from soil, skin, water and plants; 2) a meat or seafood core community, such as Firmicutes and Actinobacteria for meat and Proteobacteria and Bacteroides for seafood; and 3) a product-specific community. According to the authors, several findings emerged from this study for $\mathrm{T}_{0}$ samples. For seafood products, differences between cod and salmon microbial communities due to feeding behavior and water environment were observed according to Hansen and Olafsen (1999), and also between fresh and smoked salmon due to bacterial contamination during the washing and smoking process. These were found to primarily belong to the seafood spoilage associated bacteria Photobacterium, as shown by Mace et al. (2013). In contrast, for meat and meat products, bacterial communities identified by the authors in beef, veal and poultry samples were mostly associated to gastrointestinal or feces microbiota. Moreover, when focusing on spoiled samples, the authors highlighted (as echoed in the studies mentioned above) that the number of OTUs found in spoiled products was lower than those found in $T_{0}$ samples. The same type of organization as for $\mathrm{T}_{0}$ samples could thus be drawn with both a product-specific and a core community level. It appeared that a majority of spoilage-associated bacteria came from the $\mathrm{T}_{0}$ general core community, for which prevalence of psychrotrophic bacteria was very high, highlighting the importance of storage temperature to select these bacteria. Moreover, part of these spoilage-associated bacteria seemed to be ubiquitous since $10 \%$ of the $T_{0}$ general core community were found in all spoiled products, including B. thermosphacta, Carnobacterium spp., and Serratia/Hafnia spp., which have the particularity to be resistant to high $\mathrm{CO}_{2}$ levels (Schuerger et al., 2013), highlighting the importance of modified-atmosphere packaging (MAP) in the selection of spoilage-associated bacteria. The authors also emphasized another factor that could shape general core community: the property of the food product itself. In fact, significant changes in the bacterial communities of diced bacon could be due to its high level of salt, which could have selected halotolerant bacteria. The authors also described evolution of the subpopulation $(<5 \%)$ of these spoilage-associated bacteria in two directions. On the one hand, some species were predominant at $\mathrm{T}_{0}$ in several products, such as $P$. acnes, but became product-specific at the end of the storage (in this case, salmon fillet). On the other hand, some product-specific species found on the spoiled product were found only on this product at $\mathrm{T}_{0}$. One of the great advantages of metagenomics is to be able to identify potentially interesting new spoilage-associated bacteria through its cultureindependent strategy. Thus the authors highlighted an unidentified OTU that represents $70 \%$ of the spoiled cod fillet samples and could represent a family clade within the order Fusobacteriales.

\subsubsection{Metagenetics as a tool to help reduce food spoilage}

Metagenomics can also be used to assist in the optimization of a manufacturing process. It can be used to describe the impact of a given change on the microbiota of a food product, which is directly correlated to its taste and aspect. This could be a very interesting approach for industrial applications.

In this way, metagenetics could be used to investigate the impact of a preparation process on the microbial community of a product. To this end, Nieminen et al. (2012) studied the effect of a marinade on the microbial community of broiler fillet, with particular reference to spoilageassociated communities. The authors highlighted that marination had two opposite effects. On the one hand, it inhibited B. thermosphacta, 
Clostridium spp., and Enterobacteriaceae (Nychas et al., 2008), three well-known families of SSO. This concept of SSO was introduced by Dalgaard (2000) and is defined as the part of the total microbiota responsible for spoilage. The inhibition of these SSO could extend the shelf life of marinated products but, on the other hand, the glucose and the acetic acid contained in this marinade selected the spoilageassociated Leuconostoc gasicomitatum and its close relative L. gelidum, two other SSOs (Johansson et al., 2011). Marination also caused changes in the OTU richness. Indeed, the number of OTUs found in the marinated broiler meat was clearly lower than in the un-marinated one. The latter presented several unique taxa, which were not able to grow in the marinade. The authors pointed out that Leuconostoc spp. could be controlled by adding sodium acetate and sodium lactate to the meat preparations, as previously mentioned by Devlieghere et al. (2004).

Metagenetics could thus be used as a tool to optimize preparation process by adjusting recipes to target some SSOs in order to reduce them. That is what Stoops et al. (2015) attempted to do by studying, with a metagenetic approach, the bacterial community dynamics during cold storage of minced meat packaged under a modified atmosphere and supplemented with different preservatives: a combination of sodium lactate and sodium acetate as a default preservative, to which other additives were added: (i) a combination of potassium lactate and potassium acetate, (ii) spice extract, and (iii) ascorbic acid. However, the authors reported that it seems difficult to target only SSOs. Indeed, they obtained similar bacterial communities irrespective of the preservative used, with L. algidus and Leuconostoc sp. appearing as the dominant bacteria. This suggests that both bacteria were well adapted to this product and illustrates how difficult it is to overcome dominant flora.

In complement to the use of additive, modification of the packaging condition could have an important influence on the SSO. Thus, Ercolini et al. (2011) used metagenetic approach to monitor bacterial diversity under different packaging conditions. They demonstrated that an initial microbial population of beef was dramatically changed during storage according to the packaging condition used. For a dominant population composed of Ralstonia sp. and Limnobacter sp. at $\mathrm{T}_{0}$, storage under aerobic conditions widely selected the aerobic genus Pseudomonas sp. as the dominant population while an high-oxygen modified atmosphere packaging (MAP) used to control these aerobic Gram-negative bacteria selected $B$. thermoshpacta and Carnobacterium divergens species and, more generally, LAB (Ercolini et al., 2006). The influence of vacuum packaging on the final microbial community is more mixed since in this case there is not a dominant flora but rather several coexisting population such as Pseudomonas spp., Lactobacillus spp., Streptococcus spp., etc. On the contrary, active vacuum packaging (AVP) selected $C$. divergens as the unique dominant flora through a plastic film coated with nisin, which inhibited the growth of $B$. thermosphacta, Pseudomonas spp., and Enterobacteriaceae (Ercolini et al., 2010). The authors highlighted that meat shelf life (defined as the time necessary to achieve a mesophilic total viable count of $7 \log \mathrm{CFU} / \mathrm{g}$ ) extends with increasing selectivity of packaging conditions against spoilage-associated bacteria. Thus, for a shelf life of 7 days in aerobic storage, AVP can extend the shelf life to 44 days.

\section{Conclusion and future perspectives}

As broadly described above, there are an increasing reported number of studies using metagenetics, which deal with fresh or fermented foods in the research literature. However, despite the powerful nature of this technology, advances in information are not always ensured. Some studies remain at the taxonomic level of phyla, group or genus; the studies reporting species identification are scarcer. This is certainly an issue that metagenomics will have to face. The enhancement of these HTS technologies is consequently a significant factor if we are to further advance our study of microbial ecosystems. Continual improvement of theses sequencing techniques (i.e. with lower error rates and cost) will enlarge and deepen the understanding of microbial metagenome with the rise of metagenomic study based not only on $16 \mathrm{~S}$ rRNA. In this way, Ripp et al. (2014) used a new metagenomic approach called "All-Food-Seq," which involves untargeted deep sequencing of a foodstuff's total genomic DNA. This method makes it possible to identify species from all kingdoms of life in a given foodstuff. In this way it simultaneously enables the evaluation of the ingredient composition as well as its microbial population. Concurrently, new approaches are also essential if we are to gain a more comprehensive view of food microbiota. Thus, a multi-omic approach including metatranscriptomics and metabolomics could provide valuable information in estimating how bacteria interact with their environment and each other (Dugat-Bony et al., 2015). The combination of these different metadata will enable the study of microbial food from the cell to the community level and, in this way, will facilitate the development of genome-scale community models (Branco dos Santos et al., 2013).

\section{References}

Aldrete-Tapia, A., Escobar-Ramirez, M.C., Tamplin, M.L., Hernandez-Iturriaga, M., 2014. High-throughput sequencing of microbial communities in Poro cheese, an artisanal Mexican cheese. Food Microbiol. 44, 136-141.

Almeida, M., Hebert, A., Abraham, A.L., Rasmussen, S., Monnet, C., Pons, N., Delbes, C., Loux, V., Batto, J.M., Leonard, P., Kennedy, S., Ehrlich, S.D., Pop, M., Montel, M.C., Irlinger, F., Renault, P., 2014. Construction of a dairy microbial genome catalog opens new perspectives for the metagenomic analysis of dairy fermented products. BMC Genomics 15, 1101

Amarita, F., Yvon, M., Nardi, M., Chambellon, E., Delettre, J., Bonnarme, P., 2004. Identification and functional analysis of the gene encoding methionine-gamma-lyase in Brevibacterium linens. Appl. Environ. Microbiol. 70, 7348-7354.

Audenaert, K., D'Haene, K., Messens, K., Ruyssen, T., Vandamme, P., Huys, G., 2010. Diversity of lactic acid bacteria from modified atmosphere packaged sliced cooked meat products at sell-by date assessed by PCR-denaturing gradient gel electrophoresis. Food Microbiol. 27, 12-18.

Benson, A.K., David, J.R., Gilbreth, S.E., Smith, G., Nietfeldt, J., Legge, R., Kim, J., Sinha, R., Duncan, C.E., Ma, J., Singh, I., 2014. Microbial successions are associated with changes in chemical profiles of a model refrigerated fresh pork sausage during an 80-day shelf life study. Appl. Environ. Microbiol. 80, 5178-5194.

Bokulich, N.A., Mills, D.A., 2013. Facility-specific "house" microbiome drives microbial landscapes of artisan cheesemaking plants. Appl. Environ. Microbiol. 79, 5214-5223.

Branco dos Santos, F., de Vos, W.M., Teusink, B., 2013. Towards metagenome-scale models for industrial applications-the case of Lactic Acid Bacteria. Curr. Opin. Biotechnol. 24, 200-206.

Chaillou, S., Chaulot-Talmon, A., Caekebeke, H., Cardinal, M., Christieans, S., Denis, C., Helene Desmonts, M., Dousset, X., Feurer, C., Hamon, E., Joffraud, J.J., La Carbona, S., Leroi, F., Leroy, S., Lorre, S., Mace, S., Pilet, M.F., Prevost, H., Rivollier, M., Roux, D., Talon, R., Zagorec, M., Champomier-Verges, M.C., 2014. Origin and ecological selection of core and food-specific bacterial communities associated with meat and seafood spoilage. ISME J. 9, 1105-1118.

Chao, S.H., Huang, H.Y Chang, C.H., Yang C.H., Cheng W.S., Kang Y.H., Watanabe, K. Tsai, Y.C., 2013. Microbial diversity analysis of fermented mung beans (Lu-Doh-Huang) by using pyrosequencing and culture methods. PLoS One 8, e63816.

Dalgaard, P., 2000. Fresh and lightly preserved seafood. In: Man, C.M.D., Jones, A.A. (Eds.), Shelf life evaluation of foods. Aspen Publishers, Gaithersburg, MD, pp. 110-139.

De Filippis, F., La Storia, A., Villani, F., Ercolini, D., 2013. Exploring the sources of bacterial spoilers in beefsteaks by culture-independent high-throughput sequencing. PLoS One 8, e70222.

Delcenserie, V., Taminiau, B., Delhalle, L., Nezer, C., Doyen, P., Crevecoeur, S., Roussey, D., Korsak, N., Daube, G., 2014. Microbiota characterization of a Belgian protected designation of origin cheese, Herve cheese, using metagenomic analysis. J. Dairy Sci. 97, 6046-6056.

Devlieghere, F., Francois, K., Vereecken, K.M., Geeraerd, A.H., Van Impe, J.F., Debevere, J., 2004. Effect of chemicals on the microbial evolution in foods. J. Food Prot. 67, 1977-1990.

Dobson, A., O'Sullivan, O., Cotter, P.D., Ross, P., Hill, C., 2011. High-throughput sequencebased analysis of the bacterial composition of kefir and an associated kefir grain. FEMS Microbiol. Lett. 320, 56-62.

Doulgeraki, A.I., Ercolini, D., Villani, F., Nychas, G.J., 2012. Spoilage microbiota associated to the storage of raw meat in different conditions. Int. J. Food Microbiol. 157, 130-141. Dugat-Bony, E., Straub, C., Teissandier, A., Onesime, D., Loux, V., Monnet, C., Irlinger, F., Landaud, S., Leclercq-Perlat, M.N., Bento, P., Fraud, S., Gibrat, J.F. Aubert, J., Fer, F., Guedon, E., Pons, N., Kennedy, S., Beckerich, J.M., Swennen, D., Bonnarme, P., 2015. Overview of a surface-ripened cheese community functioning by meta-omics analyses. PLoS One 10, e0124360.

Elizaquivel, P., Perez-Cataluna, A., Yepez, A., Aristimuno, C., Jimenez, E., Cocconcelli, P.S., Vignolo, G., Aznar, R., 2014. Pyrosequencing vs. culture-dependent approaches to analyze lactic acid bacteria associated to chicha, a traditional maize-based fermented beverage from Northwestern Argentina. Int. J. Food Microbiol. 198C, 9-18. 
Ercolini, D., 2013. High-throughput sequencing and metagenomics: moving forward in the culture-independent analysis of food microbial ecology. Appl. Environ. Microbiol. 79, 3148-3155.

Ercolini, D., Russo, F., Torrieri, E., Masi, P., Villani, F., 2006. Changes in the spoilage-related microbiota of beef during refrigerated storage under different packaging conditions. Appl. Environ. Microbiol. 72, 4663-4671.

Ercolini, D., Russo, F., Nasi, A., Ferranti, P., Villani, F., 2009. Mesophilic and psychrotrophic bacteria from meat and their spoilage potential in vitro and in beef. Appl. Environ. Microbiol. 75, 1990-2001.

Ercolini, D., Ferrocino, I., La Storia, A., Mauriello, G., Gigli, S., Masi, P., Villani, F., 2010. Development of spoilage microbiota in beef stored in nisin activated packaging. Food Microbiol. 27, 137-143.

Ercolini, D., Ferrocino, I., Nasi, A., Ndagijimana, M., Vernocchi, P., La Storia, A., Laghi, L., Mauriello, G., Guerzoni, M.E., Villani, F., 2011. Monitoring of microbial metabolites and bacterial diversity in beef stored under different packaging conditions. Appl. Environ. Microbiol. 77, 7372-7381.

Ercolini, D., De Filippis, F., La Storia, A., Iacono, M., 2012. “Remake ” by high-throughput sequencing of the microbiota involved in the production of water buffalo mozzarella cheese. Appl. Environ. Microbiol. 78, 8142-8145.

Ercolini, D., Pontonio, E., De Filippis, F., Minervini, F., La Storia, A., Gobbetti, M., Di Cagno, R., 2013. Microbial ecology dynamics during rye and wheat sourdough preparation. Appl. Environ. Microbiol. 79, 7827-7836.

Esposito, A., Kirschberg, M., 2014. How many 16S-based studies should be included in a metagenomic conference? It may be a matter of etymology. FEMS Microbiol. Lett. 351, 145-146.

Felske, A., Akkermans, A.D., De Vos, W.M., 1998. Quantification of 16S rRNAs in complex bacterial communities by multiple competitive reverse transcription-PCR in temperature gradient gel electrophoresis fingerprints. Appl. Environ. Microbiol. 64, 4581-4587.

Fox, P.F., Guinee, T.P., Cogan, T.M., McSweeney, P.L.H., 2000. Fundamentals of cheese science. Aspen Publishers, Gaithersburg.

Fuka, M.M., Wallisch, S., Engel, M., Welzl, G., Havranek, J., Schloter, M., 2013. Dynamics of bacterial communities during the ripening process of different Croatian cheese types derived from raw ewe's milk cheeses. PLoS One 8, e80734.

Giraffa, G., Neviani, E., 2001. DNA-based, culture-independent strategies for evaluating microbial communities in food-associated ecosystems. Int. J. Food Microbiol. 67, 19-34.

Ha, J.H., Hawer, W.S., Kim, Y.J., J., N.Y., 1989. Changes of free sugars in kimchi during fermentation. Korean J. Food Sci. Technol. 21, 633-638.

Hansen, G.H., Olafsen, J.A., 1999. Bacterial interactions in early life stages of marine cold water fish. Microb. Ecol. 38, 1-26.

Huis in 't Veld, J.H., 1996. Microbial and biochemical spoilage of foods: an overview. Int. J. Food Microbiol. 33, 1-18.

Humblot, C., Guyot, J.P., 2009. Pyrosequencing of tagged 16S rRNA gene amplicons for rapid deciphering of the microbiomes of fermented foods such as pearl millet slurries. Appl. Environ. Microbiol. 75, 4354-4361.

Illeghems, K., De Vuyst, L., Papalexandratou, Z., Weckx, S., 2012. Phylogenetic analysis of a spontaneous cocoa bean fermentation metagenome reveals new insights into its bacterial and fungal community diversity. PLoS One 7, e38040.

Irlinger, F., Layec, S., Helinck, S., Dugat-Bony, E., 2015. Cheese rind microbial communities: diversity, composition and origin. FEMS Microbiol. Lett. 362, 1-11.

Jeong, S.H., Lee, S.H., Jung, J.Y., Choi, E.J., Jeon, C.O., 2013. Microbial succession and metabolite changes during long-term storage of Kimchi. J. Food Sci. 78, M763-M769.

Johansson, P., Paulin, L., Sade, E., Salovuori, N., Alatalo, E.R., Bjorkroth, K.J., Auvinen, P., 2011. Genome sequence of a food spoilage lactic acid bacterium, Leuconostoc gasicomitatum LMG 18811T, in association with specific spoilage reactions. Appl. Environ. Microbiol. 77, 4344-4351.

Jung, J.Y., Lee, S.H., Kim, J.M., Park, M.S., Bae, J.W., Hahn, Y., Madsen, E.L., Jeon, C.O., 2011. Metagenomic analysis of kimchi, a traditional Korean fermented food. Appl. Environ. Microbiol. 77, 2264-2274.

Jung, M.J., Nam, Y.D., Roh, S.W., Bae, J.W., 2012. Unexpected convergence of fungal and bacterial communities during fermentation of traditional Korean alcoholic beverages inoculated with various natural starters. Food Microbiol. 30, 112-123.

Jung, J., Choi, S., Jeon, C.O., Park, W., 2013a. Pyrosequencing-based analysis of the bacterial community in Korean traditional seafood, ojingeo jeotgal. J. Microbiol. Biotechnol. 23, 1428-1433.

Jung, J.Y., Lee, S.H., Jin, H.M., Hahn, Y., Madsen, E.L., Jeon, C.O., 2013b. Metatranscriptomic analysis of lactic acid bacterial gene expression during kimchi fermentation. Int. J. Food Microbiol. 163, 171-179.

Jung, J., Lee, S.H., Jin, H.M., Jeon, C.O., Park, W., 2014. Pyrosequencing-based analysis of bacterial community and metabolites profiles in Korean traditional seafood fermentation: a flatfish-fermented seafood. Biosci. Biotechnol. Biochem. 78, 908-910.

Kim, Y.S., Kim, M.C., Kwon, S.W., Kim, S.J., Park, I.C., Ka, J.O., Weon, H.Y., 2011. Analyses of bacterial communities in meju, a Korean traditional fermented soybean bricks, by cultivation-based and pyrosequencing methods. J. Microbiol. 49, 340-348.

Kim, H.J., Kim, M.J., Turner, T.L., Kim, B.S., Song, K.M., Yi, S.H., Lee, M.K., 2014. Pyrosequencing analysis of microbiota reveals that lactic acid bacteria are dominant in Korean flat fish fermented food, gajami-sikhae. Biosci. Biotechnol. Biochem. 78, 1611-1618.

Kiyohara, M., Koyanagi, T., Matsui, H., Yamamoto, K., Take, H., Katsuyama, Y., Tsuji, A., Miyamae, H., Kondo, T., Nakamura, S., Katayama, T., Kumagai, H., 2012. Changes in microbiota population during fermentation of narezushi as revealed by pyrosequencing analysis. Biosci. Biotechnol. Biochem. 76, 48-52.

Korsak, N., Taminiau, B., Leclercq, M., Nezer, C., Crevecoeur, S., Ferauche, C., Detry, E., Delcenserie, V., Daube, G., 2015. Short communication: evaluation of the microbiota of kefir samples using metagenetic analysis targeting the 16S and 26S ribosomal DNA fragments. J. Dairy Sci. 98, 3684-3689.
Koyanagi, T., Kiyohara, M., Matsui, H., Yamamoto, K., Kondo, T., Katayama, T., Kumagai, H., 2011. Pyrosequencing survey of the microbial diversity of 'narezushi', an archetype of modern Japanese sushi. Lett. Appl. Microbiol. 53, 635-640.

Koyanagi, T., Nakagawa, A., Kiyohara, M., Matsui, H., Yamamoto, K., Barla, F., Take, H., Katsuyama, Y., Tsuji, A., Shijimaya, M., Nakamura, S., Minami, H., Enomoto, T., Katayama, T., Kumagai, H., 2013. Pyrosequencing analysis of microbiota in Kaburazushi, a traditional medieval sushi in Japan. Biosci. Biotechnol. Biochem. 77 2125-2130.

Lee, S.H., Jung, J.Y., Jeon, C.O., 2014. Effects of temperature on microbial succession and metabolite change during saeu-jeot fermentation. Food Microbiol. 38, 16-25.

Lee, S.H., Jung, J.Y., Jeon, C.O., 2015. Source tracking and succession of kimchi lactic acid bacteria during fermentation. J. Food Sci. 80, M1871-M1877.

Leite, A.M., Mayo, B., Rachid, C.T., Peixoto, R.S., Silva, J.T., Paschoalin, V.M., Delgado, S. 2012. Assessment of the microbial diversity of Brazilian kefir grains by PCR-DGGE and pyrosequencing analysis. Food Microbiol. 31, 215-221.

Li, X.R., Ma, E.B., Yan, L.Z., Meng, H., Du, X.W., Quan, Z.X., 2013. Bacterial and fungal diversity in the starter production process of Fen liquor, a traditional Chinese liquor J. Microbiol. 51, 430-438.

Lipinski, B., Hanson, C., Lomax, J., Kitinoja, L., Waite, R., Searchinger, T., 2013. Reducing Food Loss and Waste. Working Paper, Installment 2 of Creating a Sustainable Food Future. World Resources Institute, Washington, DC.

Lopez-Velasco, G., Welbaum, G.E., Boyer, R.R., Mane, S.P., Ponder, M.A., 2011. Changes in spinach phylloepiphytic bacteria communities following minimal processing and refrigerated storage described using pyrosequencing of 16S rRNA amplicons. J. Appl. Microbiol. 110, 1203-1214.

Lusk, T.S., Ottesen, A.R., White, J.R., Allard, M.W., Brown, E.W., Kase, J.A., 2012. Characterization of microflora in Latin-style cheeses by next-generation sequencing technology. BMC Microbiol. 12, 254.

Lyu, C., Chen, C., Ge, F., Liu, D., Zhao, S., Chen, D., 2013. A preliminary metagenomic study of puer tea during pile fermentation. J. Sci. Food Agric. 93, 3165-3174.

Mace, S., Cornet, J., Chevalier, F., Cardinal, M., Pilet, M.F., Dousset, X., Joffraud, J.J., 2012 Characterisation of the spoilage microbiota in raw salmon (Salmo salar) steaks stored under vacuum or modified atmosphere packaging combining conventional methods and PCR-TTGE. Food Microbiol. 30, 164-172.

Mace, S., Joffraud, J.J., Cardinal, M., Malcheva, M., Cornet, J., Lalanne, V., Chevalier, F., Serot, T., Pilet, M.F., Dousset, X., 2013. Evaluation of the spoilage potential of bacteria isolated from spoiled raw salmon (Salmo salar) fillets stored under modified atmosphere packaging. Int. J. Food Microbiol. 160, 227-238.

Marsh, T.L., 1999. Terminal restriction fragment length polymorphism (T-RFLP): an emerging method for characterizing diversity among homologous populations of amplification products. Curr. Opin. Microbiol. 2, 323-327.

Marsh, A.J., O'Sullivan, O., Hill, C., Ross, R.P., Cotter, P.D., 2013a. Sequence-based analysis of the microbial composition of water kefir from multiple sources. FEMS Microbiol. Lett. 348, 79-85.

Marsh, A.J., O'Sullivan, O., Hill, C., Ross, R.P., Cotter, P.D., 2013b. Sequencing-based analysis of the bacterial and fungal composition of kefir grains and milks from multiple sources. PLoS One 8, e69371.

Marsh, A.J., O'Sullivan, O., Hill, C., Ross, R.P., Cotter, P.D., 2014. Sequence-based analysis of the bacterial and fungal compositions of multiple kombucha (tea fungus) samples. Food Microbiol. 38, 171-178.

Mayer, P., Farinelli, L., Kawashima, E.H., 1997. Method of nucleic acid amplification. Illumina, Inc., United States of America.

Muyzer, G., de Waal, E.C., Uitterlinden, A.G., 1993. Profiling of complex microbial populations by denaturing gradient gel electrophoresis analysis of polymerase chain reaction-amplified genes coding for 16S rRNA. Appl. Environ. Microbiol. 59, 695-700.

Nalbantoglu, U., Cakar, A., Dogan, H., Abaci, N., Ustek, D., Sayood, K., Can, H., 2014 Metagenomic analysis of the microbial community in kefir grains. Food Microbiol. 41, 42-51.

Nam, Y.D., Lee, S.Y., Lim, S.I., 2012a. Microbial community analysis of Korean soybean pastes by next-generation sequencing. Int. J. Food Microbiol. 155, 36-42.

Nam, Y.D., Park, S.L., Lim, S.I., 2012b. Microbial composition of the Korean traditional food "kochujang" analyzed by a massive sequencing technique. J. Food Sci. 77, M250-M256.

Nieminen, T.T., Koskinen, K., Laine, P., Hultman, J., Sade, E., Paulin, L., Paloranta, A. Johansson, P., Bjorkroth, J., Auvinen, P., 2012. Comparison of microbial communities in marinated and unmarinated broiler meat by metagenomics. Int. J. Food Microbiol. $157,142-149$

Nychas, G.J., Skandamis, P.N., Tassou, C.C., Koutsoumanis, K.P., 2008. Meat spoilage during distribution. Meat Sci. 78, 77-89.

Oki, K., Dugersuren, J., Demberel, S., Watanabe, K., 2014. Pyrosequencing analysis of the microbial diversity of airag, khoormog and tarag, traditional fermented dairy products of mongolia. Bioscisci. Microbiota, Food Health 33, 53-64.

O'Sullivan, D.J., Giblin, L., McSweeney, P.L., Sheehan, J.J., Cotter, P.D., 2013. Nucleic acidbased approaches to investigate microbial-related cheese quality defects. Front. Microbiol. 4, 1.

O'Sullivan, D.J., Cotter, P.D., Sullivan, O.O., Giblin, L., McSweeney, P.L., Sheehan, J.J., 2015 Temporal and spatial differences in microbial composition during the manufacture of a continental-type cheese. Appl. Environ. Microbiol. 81, 2525-2533.

Park, E.J., Chun, J., Cha, C.J., Park, W.S., Jeon, C.O., Bae, J.W., 2012. Bacterial community analysis during fermentation of ten representative kinds of kimchi with barcoded pyrosequencing. Food Microbiol. 30, 197-204.

Park, K.Y., Jeong, J.K., Lee, Y.E., Daily 3rd, J.W., 2014. Health benefits of kimchi (Korean fermented vegetables) as a probiotic food. J. Med. Food 17, 6-20.

Polka, J., Rebecchi, A., Pisacane, V., Morelli, L., Puglisi, E., 2015. Bacterial diversity in typical Italian salami at different ripening stages as revealed by high-throughput sequencing of 16S rRNA amplicons. Food Microbiol. 46, 342-356. 
Pothakos, V., Taminiau, B., Huys, G., Nezer, C., Daube, G., Devlieghere, F., 2014 Psychrotrophic lactic acid bacteria associated with production batch recalls and sporadic cases of early spoilage in Belgium between 2010 and 2014. Int. J. Food Microbiol. 191, 157-163.

Quigley, L., O'Sullivan, O., Beresford, T.P., Ross, R.P., Fitzgerald, G.F., Cotter, P.D. 2012. High-throughput sequencing for detection of subpopulations of bacteria not previously associated with artisanal cheeses. Appl. Environ. Microbiol. 78, 5717-5723.

Ripp, F., Krombholz, C.F., Liu, Y., Weber, M., Schafer, A., Schmidt, B., Koppel, R., Hankeln, T., 2014. All-Food-Seq (AFS): a quantifiable screen for species in biological samples by deep DNA sequencing. BMC Genomics 15, 639.

Roh, S.W., Kim, K.H., Nam, Y.D., Chang, H.W., Park, E.J., Bae, J.W., 2010. Investigation of archaeal and bacterial diversity in fermented seafood using barcoded pyrosequencing. ISME J. 4, 1-16.

Ronaghi, M., Karamohamed, S., Pettersson, B., Uhlen, M., Nyren, P., 1996. Real-time DNA sequencing using detection of pyrophosphate release. Anal. Biochem. 242, 84-89.

Sakamoto, N., Tanaka, S., Sonomoto, K., Nakayama, J., 2011. 16S rRNA pyrosequencingbased investigation of the bacterial community in nukadoko, a pickling bed of fermented rice bran. Int. J. Food Microbiol. 144, 352-359.

Santamaria, M., Fosso, B., Consiglio, A., De Caro, G., Grillo, G., Licciulli, F., Liuni, S., Marzano M., Alonso-Alemany, D., Valiente, G., Pesole, G., 2012. Reference databases for taxonomic assignment in metagenomics. Brief. Bioinform. 13, 682-695.

Schuerger, A.C., Ulrich, R., Berry, B.J., Nicholson, W.L., 2013. Growth of Serratia liquefaciens under $7 \mathrm{mbar}, 0^{\circ} \mathrm{C}$, and $\mathrm{CO} 2$-enriched anoxic atmospheres. Astrobiology 13, 115-131.
Sheridan, J.J., 1998. Sources of contamination during slaughter and measures for control. J. Food Saf. 18, 321-339.

Stoops, J., Ruyters, S., Busschaert, P., Spaepen, R., Verreth, C., Claes, J., Lievens, B., Van Campenhout, L., 2015. Bacterial community dynamics during cold storage of minced meat packaged under modified atmosphere and supplemented with different preservatives. Food Microbiol. 48, 192-199.

Sulaiman, J., Gan, H.M., Yin, W.F., Chan, K.G., 2014. Microbial succession and the functional potential during the fermentation of Chinese soy sauce brine. Front Microbiol. 5, 556.

Wolfe, B.E., Dutton, R.J., 2015. Fermented foods as experimentally tractable microbial ecosystems. Cell 161, 49-55.

Wolfe, B.E., Button, J.E., Santarelli, M., Dutton, R.J., 2014. Cheese rind communities provide tractable systems for in situ and in vitro studies of microbial diversity. Cell 158, 422-433.

Xiao, X., Dong, Y., Zhu, Y., Cui, H., 2013. Bacterial diversity analysis of Zhenjiang Yao meat during refrigerated and vacuum-packed storage by 454 pyrosequencing. Curr. Microbiol. 66, 398-405.

Xie, G., Wang, L., Gao, Q., Yu, W., Hong, X., Zhao, L., Zou, H., 2013. Microbial community structure in fermentation process of Shaoxing rice wine by Illumina-based metagenomic sequencing. J. Sci. Food Agric. 93, 3121-3125.

YalçIn, S., Nizamlioğlu, M., Gürbüz, Ü., 2001. Fecal coliform contamination of beef carcasses during the slaughtering process. J. Food Saf. 21, 225-231.

Zhao, F., Zhou, G., Ye, K., Wang, S., Xu, X., Li, C., 2014. Microbial changes in vacuum-packed chilled pork during storage. Meat Sci. 100C, 145-149. 